\title{
Technological Imperatives, Productivity and Insurance Costs: A Comment
}

\author{
by Pierre Pestieau*
}

This work bears the typical Baumol trademark. The concept of "personal services" is both intuitive and operational. The analogy between an insurance service and a string quartet performance is appealing though like any comparison it has a limited extent.

My comment will address the general issue raised by Professor Baumol, that of productivity and technological progress in insurance, and which is, as I understand it, the theme of this issue of "The Geneva Papers". It can be subdivided into several questions.

- what is the output or rather the outputs of an insurance company?

- can we measure it with the available techniques and data?

- why do we need to measure the performance of the insurance industry?

But first, I would like to come back on the productivity of a string quartet. I agree with Baumol when he writes that its productivity for a live performance cannot increase. But this is quite a narrow view. Thanks to the huge advance in the technology of communications and of transportation, good quartets can perform live before thousands of people across the world over a year. Further, they can sell their recording to millions of music lovers. This was not possible in the days of Mozart.

The nature of the output of an insurance company is puzzling. From a practical viewpoint, the company's output is the policies it issues, comparable to a car manufacturer counting the number of vehicles it produces. Of course, as they are many types of cars, one policy may be quite unlike another. To overcome this difficulty, one uses some aggregators such as prices. However, compared to the car industry, the insurance sector outputs are more heterogeneous and the prcmiums are not always a good measure of the value of policies.

Bypassing those hurdles, a number of scholars have used total premium income as the insurance company's output, but this is clearly unsatisfactory. In the light of the principles of national income accounting, an alternative approach consists of viewing the output of an insurance company as being the sum of wages (the reward to labor) and profits (the reward to capital). Note further that using either premiums income or wages plus profits gives a measure in current rather than constant prices. In other words, it does not yield a measure of real output, for which one needs to apply a price indcx.

* Université de Liège and CORE. 
One faces a real difficulty which is to measure an output that is both complex and highly qualitative. It has been suggested to list a manageable number of products lines and to determine an indicator of the relative importance to be attached to each category. But then, we comc back to the issue of how to measurc such as an indicator.' Relying on the market prices can often be misleading. Baumol uses the example of car insurance. Lct me indicate the implications of using cither valuc added on total premium as a measure of output. Over the years, one has observed an increase in the cost of automobile repairs and in careless driving which is also called moral hazard. Both phenomena increase premiums whereas thcy hardly contribute to increasing valuc added.

Therc is thus a slight inconsistency in Baumol's argument. The factors which explain why total factor productivity growth for the insurance industry has been negative over the last decades are not the same as those that one finds behind the rise in the cost of insurance, that is, in the level of premiums. The former pertain to the labor productivity of the insurance labor force and the technology of the basic insurance activitics. The latter are related to the rapid increase in the priccs of services such as health care and auto repair.

In recent years, new techniques ${ }^{2}$ have been suggested to measure the output of insurance companies. Those techniques rest on the approach of the so-called hedonic prices and on recent developments in general equilibrium theory. This leads me to the next question, the practical issue of how to get the appropriate data.

If empirical works on the insurance sector often use simplistic definitions of output such as total premium or wages plus profits, it is largely due to the unavailability of more satisfactory data. One often has to use accounting data which not only provide truncated evidence on the functioning of the sector, but which according to some practitioners are not always reliable.

It is also worth stressing that the type of data we economists need depends on what we want to ultimately measure. Baumol is mainly concerned by the evolution of labor productivity in insurance related services. In that case, 1 imagine he uses national account data for the output and available evidence for the labor force. Note in passing that in a service sector such as insurance, where the main input is labor, the calculation of labor productivity change is mainly a tautological exercisc. Indeed, the national accounts measure of production is in most countries no more than an index of labor. As implied by Baumol, to get a satisfactory measurc of productivity change, one should be able to take into account the quality dimension.

A large fraction of the empirical work on the insurance industry has been conccrned with the estimation of returns to scale using cross-sectional data for firms rather than a time series of the industry aggregates. In that work, total premium or claims are used to measure both scale and output size. If one is interested by the level and the growth of productivity, one needs detailed data on both inputs and outputs. To evaluate the level of productivity, or rather that of productivity efficiency, one wants to check whether insurance companies make the best use of the rcsources they engage in their activities. A company is accordingly deemed efficient if it cannot produce more products for the resources available to it or use

\footnotetext{
I Sce Hirshorn and Geehan (1977), O’Brien, (1991)

2 See Hornstein and Prescott (1991).
} 
less resources for the services it is using. To evaluate productive efficiency, one first constructs a "best practice" frontier and then calculates the distance between that frontier and actual operations of companies. ${ }^{3}$ We used the OECD international sectoral data base to measure the productive efficiency of financial institutions and insurance across the 15 countries concerned and over the period 1970-85. This yields efficiency measures ranging form 0.66 in Denmark to 0.96 in Japan. ${ }^{4}$

Instead of focusing on the level of efficiency, one can be interested by the growth of total factor productivity. This is the viewpoint adopted by Baumol and also by Wolff (1991). Using data from the U.S. National and Income and Product Accounts, the latter computes the total factor productivity growth for the U.S. insurance industry. Using the OECD data, this has been done by Englander and Mittelstädt (1988) for financial institutions and insurance in most OECD countries. They find rates declining from $1.2 \%$ in $1970-1973$ to $-0.3 \%$ in 1979-1983 for eleven member countries. An alternative approach is to estimate a best practice frontier which allows for computing both a rate of technical progress and a rate of variation in technical efficiency. The sum of those two rates assumedly approximates the rate of growth of total factor productivity measure. Using this method, we show that over the whole period annual change in total factor productivity has been positive and equal to $0.4 \%$ but this can be decomposed into a positive rate of technical progress of $0.7 \%$ and a negative change in productive efficiency of $-0.26 \% .{ }^{5}$

Those OECD figures are not entirely satisfactory. They are much too aggregate and they provide too rough figure for the output of the insurance industry. To correctly assess the level and the growth of both technology and efficiency, one ought to proceed at the level of insurance companies and with a larger set of data than that based on national accounts or on the financial statements of companies.

I thus conclude with a plea: ladies and gentlemen of the insurance industry give us more data. That way, we will be able to get a better understanding of what is going on in your sector in terms of productivity growth, technical efficiency, scale and scope economies. This could constitute welcome and useful information for all of us, practitioners and scholars, to better prepare for the challenge of tomorrow.

${ }^{3}$ See, e.g., Fecher et al. (1991).

${ }^{4}$ See Pestieau (1991).

${ }^{5}$ Pestieau (1991). 


\section{REFERENCES}

BAUMOL, W. (1991), Technological imperatives, productivity and insurance costs. The Geneva Papers, this issue.

ENGLANDER, A. S. and MITTELSTÄDT, A. (1988), Lá productivité totale des facteurs: aspects macroéconomiques et structurels de son ralentissement, Revue Economique de l'OCDE, 10, 8- 64 .

FECHER, F. KESSLER, D., PERELMAN, S. and PESTIEAU, P. (1991), Productive performance of the French insurance industry, mimeo.

HIRSHORN, R. and GEEHAN, G. (1977), Measuring the real output of the life insurance industry, Review of Economics and Statistics, 59, 211-219.

HORNSTEIN, A. and PRESCOTT, E. (1990). On measuring the output of insurance business, Federal Review Bank of Minneapolis, Working Paper No. 447.

O'BRIEN, C. D. (1991), Measuring the output of life insurance companies, The Geneva Papers, this issue.

PESTIEAU, P. (1991), Performance and competition in services, mimeo.

WOLFF, E. (1991), Productivity growth, capital intensity, and skill levels in the U.S. insurance industry, 1948-86, The Geneva Papers, this issue. 